\title{
Die Nederlandse skoolidentiteitshandhawing en die betekenis daarvan vir Suid-Afrika
}

\author{
J.A. Rens \& J.L. van der Walt \\ Skool vir Onderwysersopleiding \\ Potchefstroomse Universiteit vir $\mathrm{CHO}$ \\ POTCHEFSTROOM
}

\begin{abstract}
The maintaining of identity in the Netherlands and the relevance for South Africa

This article focuses on two questions: The way in which the issue of identity has been handled in the Netherlands since the 16th century and which perspectives the history of Dutch education provides for the issue of identity in South African education in a post-apartheid dispensation.

It is indicated that the process/history of maintaining the identity of the Christian school in the Netherlands was one of continuous conflict between the Christian and the neutral (secular) school. In 1920 the first phase of the conflict was resolved fairly satisfactorily with the "De Visserwet" (act), which granted parents the right to organise own schools. Since then all schools have been funded on an equal base by the state. As South Africa is currently trying to find solutions to certain educational problems, solutions resulting from the Dutch situation could possibly be applied partially to the South African situation. The main advantage would be that a variety of groups with different life views would be able to exist in harmony and to organise and support own schools receiving equal state support.
\end{abstract}

\section{Inleiding en probleemstelling}

In hierdie artikel word die Nederlandse geskiedenis van religieuslewensbeskoulike identiteitshandhawing in die Christelike skool en onderwys sedert die Reformasie $(+1600)$ tot die huidige tyd kursories 
nagegaan ten einde vas te stel of enige gesigspunte op grond van hierdie onderwysgeskiedenis vir die onderwyssituasie in die Suid-Afrika van die toekoms (na 1994) gevind kan word. Vir die doel van hierdie artikel word met identiteit die lewensbeskoulike gees en rigting van die onderwys bedoel. Identiteit het dus te doen met die besondere karakter van 'n betrokke skool (Harinck, 1987:15). Die identiteit van 'n betrokke skool vind uitdrukking in die volgende fasette daarvan: die wese en doel van die skoolse opvoedende onderwys, die inhoud, die tug, metode, finansies, toesig en beheer daarvan, die rol van die ouer, gemeenskap en staat in die skool en die rol van die onderwyser in die skoolse opvoedende onderwys.

Daar word gepoog om die volgende twee vraagstukke te behandel:

* Die wyse waarop lewensopvatlike identiteit in die Nederlandse onderwys vanaf 1600 n.C. tot tans gehanteer is.

* Die insigte wat hierdie Nederlandse onderwysgeskiedenis moontlik vir die hantering van hierdie soort identiteit in die onderwys in SuidAfrika in die post-apartheidsbedeling kan bied.

Die doel van die aanvanklike navorsing (waarop hierdie artikel gebaseer is) was uiteraard om bogenoemde vrae te beantwoord. Daar is gebruik gemaak van onder andere die probleem-historiese metode, wysgerige metodes, onderhoude, die prinsipieel-besinnende metode, prinsipiële beskrywing en die transendentaal-kritiese metode.

Dié ondersoek het aan die lig gebring dat lewensopvatlike identiteit in die Nederlandse onderwys in twee lewensbeskoulike strominge gestalte gekry het, naamlik in terme van die Christelike skool en van die liberaalhumanistiese skool. Deur die eeue het die Christelike skool in Nederland 'n stryd gevoer om sy Christelike identiteit te handhaaf en te behou teenoor die liberaal-humanistiese skool, en veral ook die gees van die tyd. Suid-Afrika bevind hom ook na 1994 in 'n situasie waar die Christelike openbare skool nie meer in die toekoms deur wetgewing beskerm gaan wees nie. Om hierdie rede word gepoog om in die Nederlandse onderwysgeskiedenis insigte te soek vir die skoolse onderwys in die SuidAfrika van die toekoms, spesifiek vir die wyse waarop die Christelike skool sy identiteit in 'n sekulêr-humanistiese samelewing sal kan handhaaf. Suid-Afrika het sedert 1994 'n sekulêr-humanistiese regstaat 
geword - 'n situasie wat beteken dat die regering sogenaamd lewensbeskoulik neutraal optree en dat die fundamentele regte van individue voorrang geniet.

\section{Die Nederlandse benadering tot religieus-lewens- beskoulike identiteitshandhawing}

In hierdie afdeling van die artikel word 'n historiese oorsig gegee van die religieus-lewensbeskoulike identiteitshandhawing in Nederland gedurende die $17 \mathrm{de}$ en $18 \mathrm{de}$ eeu. Die Nederlandse volk sowel as die destydse Nederlandse regerings het met die aanvang van die $17 \mathrm{de}$ eeu 'n homogeen Christelike karakter vertoon (Idenburg, 1964:78). Die Hervormde Kerk was indertyd die staatskerk en het die onderwys georganiseer (Kuiper, 1904:12). Die openbare (staat-)skool het 'n duidelike en onmiskenbare Christelik-Reformatoriese (Bybelse) karakter/identiteit vertoon en daar is allerweë daarna verwys as die skool met die Bybel (Gilhuis, 1974:6; Gilhuis, 1975a:32). Hierdie skool het ten doel gehad om die kind voor te berei vir 'n lewe ter verheerliking van God se Naam (Coetzee, 1963:190; vgl. Bregman, 1981:78). Hierdie doel het die skering en inslag gevorm van die identiteit van die Christelike skool. Christelike onderwys het behels dat die inhoud en metode van aanbieding sodanig was dat die eer van God daardeur gesoek kon word.

Weens verslapping in Christelike godsdienstigheid by die breë volksmassa in die loop van die 18de eeu het allerlei liberaal-humanistiese strominge die geleentheid gekry om hulle onderskeie invloede in die Nederlandse samelewing en dus ook in die onderwys te laat geld (vgl. Van Prinsterer, 1876:433; Rens, 1993:19). Amos Comenius (1592-1670) het byvoorbeeld begin om die Realisme te predik, een van die lewensbeskoulike rigtings wat die Christelike identiteit van die skool bedreig het. Die opvoedingsdoel van die Realisme was byvoorbeeld om die kind so voor te berei vir die werklike lewe dat hy sy eie geluksaligheid kon bewerkstellig (Coetzee, 1963:214; vgl. Bigot \& Van Hees, 1963:80).

Ook die Rasionalisme, soos dit byvoorbeeld tot uiting gekom het in die werke van René Descartes (1596-1650), het die Christelike identiteit van die skool in gevaar gestel omdat dit die teoretiese rede van die mens oorbeklemtoon het en onder meer aangevoer het dat die jeug opgevoed 
Die Nederlandse skoolidentiteitshandhawing en die betekenis daarvan vir Suid-Afrika

moes word tot goeie staatsburgerskap (Pounds, 1968:175; Kalsbeek, 1977:19). Die rasionalistiese geestesklimaat van die $18 \mathrm{de}$ eeu, wat bekend staan as die Aufklärung of Verligting (Klapwijk, 1971:12), het grootskaalse sekularisasie van die samelewing meegebring, aangesien dit die kerk se invloed ten gunste van liberalistiese invloede op die mens verminder het (Vogelaar \& Bregman, 1984:16). Uit hierdie Verligtingsgees vloei daar ander filosofiese strominge voort - byvoorbeeld die Romantisisme (Klapwijk, 1971:16), die Naturalisme (Van der Linde, 1984:128-129) en die staatkundige denke (wat egter nie as 'n lewensbeskoulike stroming beskou kan word nie) (Klapwijk, 1971:17). Volgens Jean-Jacques Rousseau, 'n romantisis en naturalis, moes die kind byvoorbeeld so opgevoed word dat sy natuurlike goedheid bewaar kon bly en sodat hy 'n goeie staatsburger kon word (Nagels \& Vandeschoor, 1977:605). Hierdie denkrigting maak 'n duidelike bydrae tot die uitbreek van die Franse Rewolusie in 1789. Die gees van hierdie Rewolusie spoel ook oor na Nederland in die 19de eeu.

Al die bovermelde strominge het gesamentlik 'n meer pragmatiese benadering tot die onderwys meegebring - ' $n$ benadering wat daartoe gelei het dat die openbare skoolse onderwys in Nederland mettertyd grootliks sy Christelike karakter/identiteit ingeboet het (Van Prinsterer, 1876:696). Maatskaplike en sosiale nuttigheid, tesame met die persoonlike vorming van die mens, het die inhoud van die nuwe onderwys geword (Rens, 1993:29). Skeiding tussen kerk en staat in 1796 (as gevolg van die totstandkoming van die Bataafse Republiek) het verder onvermydelik tot die sekularisasie van die Nederlandse samelewing bygedra (vgl. Grossheide \& Van Itterzon, 1960:158; Burggraaf, 1981a:11).

\section{Die identiteitshandhawing van die Christelike skool in Nederland gedurende die 19de eeu}

In Nederland is die 19de-eeuse onderwys gekenmerk deur 'n lang en fel skoolstryd. Hierdie stryd was gekenmerk deur die voorstanders van Christelike onderwys se strewe om die reg te verkry om lewensbeskoulikeie skole op te rig (vgl. Rens, 1993:47). J.H. van der Palm se "Wet op het Lager onderwijs" van 1801 en 1803 het bepaal dat die openbare skole kinders moes vorm tot deugsame mense en nuttige lede van die maatskappy, en dat alle leerstellige verskille in die onderwys uitgeskakel 
J.A. Rens \& J.L. van der Walt

moes word (Kuiper, 1904:42). Vir die voorstanders van die Christelike onderwys was hierdie ideale onaanvaarbaar, omdat so 'n onderwysdoel volgens hulle wêrelds was en die kind nie meer tot eer van God opgevoed sou word nie. Die openbare of staatskool het volgens hulle sy besondere Christelike karakter/identiteit verloor en daardeur 'n waardelose neutrale skool geword.

Die neutrale karakter van die openbare skool het verder beslag gekry met A. van der Ende se "Wet op het Lager onderwijs" van 1806, wat bepaal het dat alle kinders sonder onderskeid van godsdienstige rigting opgevoed moes word tot alle maatskaplike en algemene Christelike deugde (Wouters \& Visser, 1926:233). Die voorstanders van Christelike onderwys het besluit om besondere skole op te rig ten einde die Christelike lewensbeskoulike identiteit van die skole te behou. Hul het op hierdie stap besluit hoewel dit uiters moeilik was om toestemming daarvoor te kry, en daarom is baie besondere skole opgerig sonder dat amptelike toestemming verkry is. Besondere skole is veral opgerig deur ouers wat deel was van die kerklike Afskeiding van 1834 (Kalsbeek, 1963:132-133; Van Brummelen, 1986:17). Die Afgeskeidenes was persone wat leerstellige probleme in die Hervormde Kerk ondervind het en wou terugkeer na die ware gereformeerde leer (Weiler et al., 1963:253).

In 1848 volg daar egter 'n Grondwethersiening wat die weg gebaan het vir die voorstanders van besondere (waaronder Christelike) onderwys om lewens- en wêreldbeskoulik eie skole op te rig (vgl. Idenburg, 1946:89). Hierdie Grondwet bepaal dat openbare onderwys die voorwerp is van die voortdurende sorg van die regering, terwyl die besondere (lewens- en wêreldbeskoulik-eie) onderwys finansieel selfvoorsienend moes wees (vgl. De Ruiter, 1963:15; Van Hulst, 1970:7). Die onderwyswet van 1857 (deurgevoer deur J.J.L. van der Brugghen) was 'n belangrike deurbraak in die stryd ter verkryging van eie Christelike skole, omdat owerheidstoestemming nie meer nodig was nie. Daar was egter van staatsweë nog geen finansiële gelykberegtiging vir alle skole nie (De Jong, 1989:169). Hierdie situasie is vergelykbaar met die situasie in die onderwys in Suid-Afrika tot in 1994 waar die per capita-toedeling uit die staatsbegroting nie vir alle skoolgaande kinders gelyk was nie.

Die skoolstryd in Nederland het in der waarheid gewentel rondom die 
vraagstuk van die identiteit van die skool en spesifiek dié van die Christelike skool. In die tweede helfte van die 19de eeu het die owerheid geëis dat die skoolstryd beëindig moes word voordat verdere Grondwethersiening in die vooruitsig gestel kon word (Gilhuis, 1975b:165). Nadat sodanige Grondwethersiening in 1886 deurgevoer is, het die daarby behorende laeronderwyswet van 1889 bepaal dat die besondere skool voortaan ook deur die staat gesubsidieer sou word. Op dié manier is 'n fase van die skoolstryd ingelui wat op die lange duur (1920) tot gelykstelling tussen openbare en besondere onderwys sou lei (Wouters \& Visser, 1926:337; Gilhuis, 1975b:173). Die besondere Christelike skool het dit dus al hoe makliker gevind om sy identiteit uit te bou en te handhaaf in die Nederlandse samelewing.

Met die eeuwisseling het openbare skole en besondere skole in Nederland dus naas mekaar gestaan, en die ouergemeenskap het 'n keuse gehad van die skool waarin hulle hul kinders wou plaas.

\section{Nederlandse identiteitshandhawing in die onderwys gedurende die 20ste eeu}

Abraham Kuyper, wat hom al gedurende die 19de eeu beywer het vir die handhawing van die Christelike besondere skool, het tydens die eeuwisseling prominent na vore getree in die onderwysstryd. Op sy aandrang het 'n staatskommissie die moontlikheid van verdere Grondwethersiening ondersoek en aanbeveel dat openbare en besondere skole finansieel presies eners deur die owerheid behandel moes word (Wouters \& Visser, 1926:342; De Ruiter, 1963:22).

Die daaropvolgende Grondwethersiening van 1917 het gepaard gegaan met 'n pacificatie (vredesluiting) tussen die sosiaal-demokratiese arbeidersparty (SDAP) en die Anti-Rewolusionêre Party van Kuyper (Van Hulst, 1970:5; De Jong, 1989:183). 'n Kompromis is naamlik bereik wat almal bevredig het: die SDAP het stemreg beding vir arbeiders en vroue, en die Anti-Rewolusionêres het die vryheid van die onderwys en finansiële gelykstelling van besondere (eie) skole in ruil vir hierdie toegewing ontvang. Die taak is opgedra aan Johan Theodoor de Visser as die heel eerste Minister van Onderwys, Kuns en Wetenskap van Nederland om 'n nuwe "Lageronderwijswet" te ontwerp (Puchinger, 1970:2). Die 
aanvaarding van sy voorstelle in 1920 het 'skoolvrede' in Nederland beteken en het volle finansiële gelykstelling tussen openbare en besondere skole meegebring (Guiaux, 1970:28; Vogelaar \& Bregman, 1984:17).

Die Laeronderwyswet van 1920 het voorts onder meer tot gevolg gehad dat die Nederlandse samelewing van toe af ingedeel is volgens lewens- en wêreldbeskouinge. Hierdie verdeling staan bekend as versuiling. Sturm (1988:58) beskryf versuiling as die raamwerk waarin die mens sy sosiaalkulturele en politieke aktiwiteite verrig of uitvoer binne sy eie lewensbeskoulike kring. Versuiling het uiteindelik daartoe gelei dat die leerlingtal in besondere onderwys vir die tydperk $1910-1980$ van $38 \%$ tot $68 \%$ van die totale leerlingbevolking in Nederland gestyg het (Koekkoek, 1992:324), terwyl die leerlingtal in die openbare onderwys dienooreenkomstig gedaal het.

Daar is veral drie rigtings in die besondere onderwys herkenbaar, naamlik die Rooms-Katolieke, die Protestant-Christelike en ook die 'neutrale' besondere onderwys (Guiaux, 1970:28). Daar bestaan ook ander besondere skole soos byvoorbeeld Joodse skole, Islamitiese skole, Hindoeskole, 'n Jogaskool en antroposofiese skole (Blaauwendraat $e t$ al., 1993:1). Die openbare skool is nie noodwendig 'neutraal' of antigodsdienstig nie, maar word beskou as 'n ontmoetingsplek waar die jeug voorberei kan word om saam te lewe en te werk met mense van ander godsdienstige of lewensbeskoulike oortuiging (Doom, 1970:38).

Volgens 'n mondelinge mededeling (Ouweneel, 1992) het latere wette, soos byvoorbeeld die 'Mammoetwet' (Wet op Voortgesette Onderwys) (Wet 314 van 1968), nie die kembepalings, soos finansiële gelykberegtiging van die 1920-wet verander nie, met die gevolg dat hierdie bepalings selfs vandag nog geld.

Sedert die sewentigerjare is daar egter ' $n$ nuwe skoolstryd in Nederland aan die gang, te wete een wat ontsuiling in die oog het (Burggraaf, 1981b:234). Daar is byvoorbeeld aangedring dat van die verskillende suile afgesien moes word en sogenaamde samewerkingskole gestig moes word (Burggraaf, 1981b:233). Die sekularisering van die samelewing en die gepaardgaande afplatting van lewensbeskoulike verskille tussen die suile het daartoe gelei dat die Protestants-Christelike suil in so 'n mate sy identiteit of aard verloor het dat baie reformatoriese Christene hulleself nie 
meer daarin tuis gevoel het nie (vgl. Oskam, 1992:11; Blaauwendraat et al., 1993:6). In reaksie teen hierdie vervlakking het 'n nuwe Christelikreformatoriese suil ontstaan, wat hom duidelik verbonde voel met die beginsels van die Reformasie (Blaauwendraat et al., 1993:6).

\section{Enkele insigte vir die Suid-Afrikaanse situasie}

Die Nederlandse onderwysgeskiedenis kan moontlik sekere perspektiewe open op identiteitshandhawing binne die konteks van die Suid-Afrikaanse onderwyssituasie. Net soos Christelike onderwys gedurende die $17 \mathrm{de}$ eeu in Nederland afdwingbaar gemaak is deur die wetgewing van 'n Christelike staat was Suid-Afrika ook tot in 1993 (minstens nomineel) 'n Christelike staat wat Christelike openbare onderwys begunstig het. $68 \%$ van die Suid-Afrikaanse bevolking het byvoorbeeld tydens die jongste sensusopname nog te kenne gegee dat hulle Christene is (Suid-Afrikaanse Statistiekdiens, 1992:1.18). Die openbare of staatsonderwys het in die 17de-eeuse Nederland, soos in Suid-Afrika tot in 1993, 'n onmiskenbare Christelike karakter vertoon. Die Nederlandse staatskool het egter reeds in die 17de en 18de eeu sy Christelike karakter/identiteit verloor, terwyl dié situasie hom eers na 1994 in Suid-Afrika voordoen.

Omdat die staat en owerheid in Suid-Afrika na 1994 nie meer uitgesproke Christelik is nie, beteken dit dat Christelike onderwys ook nie meer deur die staat afdwingbaar gemaak of voorsien gaan word nie (vgl. die bepalings van die Grondwet, Hoofstuk 3, Wet 200/1993). So 'n toedrag van sake beteken dat voorstanders van Christelike onderwys hulle ideale sal moet handhaaf in 'n gesekulariseerde omgewing soos dit reeds in die $17 \mathrm{de}$ en $18 \mathrm{de}$ eeu in Nederland die geval was.

Daar is vir die onderwys in Suid-Afrika na 1994 moontlik heelwat te leer uit die Nederlandse onderwysgeskiedenis van die 20ste eeu. Finansiële gelykberegtiging van besondere en openbare onderwys soos bepaal deur die 1920-Onderwyswet van Nederland is byvoorbeeld 'n noodsaaklikheid vir onderwys in die toekomstige Suid-Afrika. Dit beteken dat alle skole, ongeag ras, kleur of geloofsoortuiging, dieselfde per capita-toewysing behoort te ontvang. In die tydperk voor 1994 was die per capitatoewysing byvoorbeeld R3 $082-00$ per blanke leerling teenoor R764-00 per swart leerling (Soal, 1990:4). Versuiling, waarvolgens die verskillende godsdienstige of lewensbeskoulike groepe in Suid-Afrika 
elkeen in sy eie raamwerk funksioneer, sal verder kan meebring dat elke groep eie lewensbeskoulik-tipiese skole en samelewingstrukture tot stand sal kan bring en finansier.

Die openingstoespraak van die Staatspresident van die Republiek van Suid-Afrika op 2 Februarie 1990 het ingrypende staatkundige en onderwysveranderings in Suid-Afrika van stapel gestuur. Hierdie aankondigings het momentum gegee aan 'n staatkundige hervormingsproses wat ook die onderwys in Suid-Afrika ten nouste geraak het (vgl. De Klerk, 1990:par. 8). Die verskillende bevolkingsgroepe in Suid-Afrika se onderwys vertoon egter nog steeds prinsipiële knelpunte. Om hierdie knelpunte uit die weg te ruim word allerweë geëis dat pariteit ten opsigte van die per capita-toewysing uit die staatsbegroting moet wees. Ook word verwag dat skoolplig vir alle Suid-Afrikaanse kinders ingestel word, dat die opleiding van onderwysers en die oopstelling van staatskole 'n realiteit sal word. Al hierdie eise bring egter verdere probleme in die onderwys na vore, soos die gebruik/misbruik van onderwys vir politieke doeleindes, die behoud/daling van standaarde, die aard van kurrikula, die toekenning van sertifikate vir bevordering, die taalmedium- of voertaalkwessie in die onderwys. Dié hervorminge laat ontstaan ook vrae oor die kulturele identiteit van die skool en die handhawing van die lewensbeskoulike identiteit van die skool (vgl. Van der Walt, et al., 1993:23-24; Rens, 1993:74-78).

Die Christelike skool in Suid-Afrika gaan hom in die toekoms waarskynlik in die posisie bevind dat hy sal moet stry vir die behoud van sy Christelike identiteit of karakter. Dié skool sal homself moet handhaaf te midde van ander skole wat in terme van gees en karakter van hom gaan verskil (Rens, 1993:77-78; Van der Walt, 1992:16-17).

Die navorsing wat hierdie artikel ten grondslag lê, het bewys dat enkele van die oplossings wat in Nederland vir onderwysprobleme aldaar oor die afgelope meer as drie eeue bedink is, met aanpassings ook in Suid-Afrika toegepas kan word. So byvoorbeeld kan die volgende as moontlike oplossing/s vanuit die Nederlandse ervaring vir soortgelyke probleme in Suid-Afrika beskou word:

* Finansiële gelykberegtiging vir alle skole moet as uitgangspunt geld: finansiële voorsiening vir alle skole moet dus - ongeag hulle 
lewensbeskoulike identiteit - per kop gelyk moet wees ter versekering van onderwyspariteit.

* Daar moet ruimte wees vir versuiling (groepvorming) in die samelewing, sodat elke godsdienstig-lewensbeskoulike groep kan funksioneer met eie skole en samelewingstrukture. Dit sal beteken dat verskillende groepe hulle eie besondere skole kan oprig ten einde 'n eie besondere identiteit te handhaaf. Daarmee word ook erkenning gegee aan die diversiteit van godsdienste en gelowe in Suid-Afrika en word gehandel in ooreenstemming met artikels 8, 14, 32(c), 34 en 247 van die Tussentydse Grondwet (200/1993) van die Republiek van SuidAfrika, wat in 1994 'n regstaat geword het.

\section{Slotsom}

Die ondersoek oor die hantering van godsdienstige en/of lewensopvatlike identiteit in die Nederlandse onderwys sedert die Reformasie wat in hierdie artikel 'n neerslag gevind het, het aan die lig gebring dat dit wel vir die Christelik-reformatoriese skool moontlik is om sy unieke identiteit te bly handhaaf in ' $n$ multi-religieuse en -lewensbeskoulike samelewing. Dit is egter belangrik dat die diversiteit van tale en kulture in só 'n samelewing erken sal word en dat verdraagsaamheid aan die orde van die dag moet wees. Dit is verder van groot belang vir Suid-Afrika dat onderwys op 'n opvoedkundig verantwoordbare wyse op gelyke wyse aan alle kinders van skoolgaande ouderdom voorsien word, met inagneming van die godsdiens, lewensbeskouing, kultuur en taal van elke kind. Vir ouers beteken dit dat daar 'n groter mate van betrokkenheid by hulle kinders se skool sal moet wees. Die mate van betrokkenheid van Christenouers by die skool sal bepaal in watter mate die Christelike skool sy Christelik-reformatoriese aard sal kan bly handhaaf in so 'n pluralistiese samelewing. Waar die ouers seggenskap gaan hê oor die inhoud, beheer en etos van 'n skool, sal die staat en owerheid se betrokkenheid beperk bly tot die finansiering van die skoolse onderwys en die stel en handhawing van standaarde en goeie orde by skole.

\section{Bibliografie}

BIGOT, L.C.T. \& VAN HEES, G. 1963. Verleden en heden. Groningen : Wolters. 
J.A. Rens \& J.L. van der Walt

BLAAUWENDRAAT, E., KOLE, I.A. \& VAN DER WALT, J.L. 1993.75 jaar vrijheid en pluriformiteit van het (basis) onderwijs in Nederland. Ongepubliseerde referaat.

BREGMAN, C. 1981. Wat willen we met ons onderwijs? (In Bregman, C. \& Kole, I.A., reds. Visie op het onderwijs. Contouren van een gereformeerde beschouing van de school. Kampen : Kok. p. 78-91.)

BURGGRAAF, M. 1981a. Waardebepaling van het Christelijk onderwijs. (In Bregman, C. \& Kole, l.A., reds. Visie op het onderwijs. Contouren van een gereformeerde beschouing van de school. Kampen : Kok. p. 10-15.)

BURGGRAAF, M. 1981b. De nieuwe schoolstrijd. (In Bregman, C. \& Kole, I.A., reds. Visie op het onderwijs. Contouren van een gereformeerde beschouing van de school. Kampen : Kok. p. 233-237.)

COETZEE, J.C. 1963. Inleiding tot die Historiese Opvoedkunde. 3de uitgawe. Johannesburg: Voortrekkerpers.

DE JONG, K. (Ozn). 1989. De Protestanten en het onderwijs. (In De Bruijn, J. red. Bepaald gebied. Aspekten van het protestantz-christelijk leven in Nederland in de jaren 1880-1940. Baarn : Ten Have. p. 166-188.)

DE KLERK, F.W. 1990. Staatspresident se openingsrede. Debatte van die Parlement (Hansard). Tweede Sessie - Negende Parlement. Vrydag 2 Februarie 1990. p. 1-18.

DE RUITER, A.C. 1963. Kaart van het onderwijs in Nederland. Kampen : Kok.

DOORN, I. 1970. Het openbaar onderwijs onder de Lager-onderwijswet 1920. Uitleg: Weekblad van het Departement van Onderwijs en Wetenschappen, 225:36-38, Des.

GILHUIS, T.M. 1974. Profiel van een school met de Bijbel. Kampen : Kok.

GILHUIS, T.M. 1975a. Christelijk onderwijs - spiegel van bevrijding. (In Gilhuis, T.M. \& De Jong, K. reds. Christelijk voortgezet onderwijs - hoe bestáát dat? Kampen : Kok. p. 11-35.)

GILHUIS, T.M. 1975b. Memorietafel van het Christelijk onderwijs. Kampen : Kok.

GROSSHEIDE, F.W. \& VAN ITTERZON, J. 1960. Christelijke encyclopedie, deel V. Kampen : Kok.

GUIAUX, G. 1970. De ontwikkeling van het bijzonder onderwijs onder de Lager Onderwijswet 1920. Uitleg: Weekblad van het Departement van Onderwijs en Wetenschappen, 225:28-35, Des. 30.

HARINCK, C. 1987. Hij zocht een zaad Gods. (In Bregman, C. \& Kole, I.A. reds. Visie op het onderwijs. Contouren van de reformatorische school nader ingevuld. Kampen : Kok. p. 12-16.)

IDENBURG, P.J. 1946. Machten en krachten in het Nederlandse schoolwezen. Amsterdam : Ploegsma. 
IDENBURG, P.J. 1964. Schets van het Nederlandse schoolwezen. Groningen : Wolters.

KALSBEEK, L. 1963. Theologische en wijsgerige achtergronden van de verhouding van kerk, staat en school in Nederland. Kampen : Kok.

KALSBEEK, L. 1977. Een school met of zonder Bijbel? Kampen : Kok.

KOEKKOEK, A.K. 1992. De school aan de ouders, 1917-1992. Bestuursforum, December.

KLAPWIJK, J. 1971. Oriëntatie in de nieuwe filosofie. Amsterdam : Paedagogisch Seminarium aan de Vrije Universiteit.

KUIPER, J. 1904. Geschiedenis van het christelijk lager onderwijs in Nederland (16 n.C. - 1904). Groningen : Wolters.

NAGELS, L. \& VANDESCHOOR, L. 1977. Grote Nederlandse Larousse Encyclopedie, deel 17. Masselt : Heideland-Orbis N.V.

OSKAM, L. 1992. Welke kenmerken maken een school tot een Reformatorische school? - een ondersoek naar de identiteit van het reformatorische onderwijs. Ongepubliseerde navorsingsverslag. Gouda, de Driestar.

OUWENEEL, W.J. 1992. Onderhoud met J.L. van der Walt en J.A. Rens. Potchefstroom, 31 Aug. (Notas beskikbaar by skrywers.)

POUNDS, R.L. 1968. The Development of Education in Western Culture. New York : Appleton-Century-Crofte.

PUCHINGER, G. 1970. Enkele opmerkingen en stemmen oor dr. J. Th. de Visser. Uitleg: Weekblad van het Departement van Onderwijs en Wetenschappen, 225:2-4, Des. 30.

RENS, J.A. 1993. Identiteit as vraagstuk in die Nederlandse onderwys en die betekenis daarvan vir Suid-Afrika. Potchefstroom : PU vir CHO. (Verhandeling - M.Ed.)

STURM, J.C. 1988. Een goede gereformeerde opvoeding. Kampen: Kok.

SOAL, P. 1990. Finansiering van die onderwys. Die Transvaler: 4, Maart 1.

SUID-AFRIKA. 1993. Grondwet van die Republiek van Suid-Afrika. Wet no. 200/1993. Pretoria : Staatsdrukker.

SUID-AFRIKAANSE STATISTIEKDIENS. 1992. Bevolking: geloof. 1.18 . Pretoria : Staatsdrukker.

VAN BRUMMELEN, H.W. 1986. Telling the Next Generation. Lanham : University Press of America.

VAN DER LINDE, H.J. 1984. Mensbeskouing en opvoeding - 'n reformatoriese perspektief. Bloemfontein : UOVS. (Proefskrif - D.Ed.)

VAN DER WALT, J.L. 1992. Enkele prinsipiële onderwysvraagstukke vir die toekomstige RSA. Potchefstroom : PU vir CHO. (Instituut vir Reformatoriese Studies.) 
VAN DER WALT, J.L., BLAAUWENDRAAT, E. \& KOLE, I.A. 1993. Die unieke identiteit van die Christelike skool in die toekomstige Suid-Afrika. Potchefstroom : PU vir CHO. (Instituut vir Reformatoriese Studies.)

VAN HULST, J.W. 1970. De wording van een wet. Uitleg: Weekblad van het Departement van Onderwijs en Wetenschappen, 225:5-11, Des. 30.

VAN PRINSTERER, G. 1876. Handboek der geschiedenis van het vaderland. Amsterdam : Höveker \& Zoon.

VOGELAAR, D. \& BREGMAN, C. 1984. School, maatschappij en cultuur in Bijbels licht. Hendrik Ido Ambacht : Begeleidingscentrum Gereformeerd Schoolonderwijs.

WEILER, A.G., DE JONG, O.J., ROGIER, L.J. \& MÖNNICH, C.W. 1963. Geschiedenis van de kerk in Nederland. Antwerpen : Aula-Boeken.

WOUTERS, D. \& VISSER, W.J. 1926. Verdieping en belijning - studies over opvoeding en onderwijs (no. 29). Groningen : Noordhoff. 
